\title{
A Comparison of the Programmes Using Finite Element Software in Electrical Machine Design
}

\author{
Murat TÖREN *1 ${ }^{1}$ Mehmet ÇELEBí ${ }^{2}$
}

Accepted $3^{\text {rd }}$ September 2016

\begin{abstract}
Electrical machines technology has become too dependent on finite element method (FEM) programs in our time. In this study, three programs that are sold commercially are compared over a 4-poles asynchronous machine of $1.1 \mathrm{~kW}$. With this comparison, it is investigated how close the values obtained by convenience, appearance, integration and, in particular, torque calculations with the real values will be. For this, the mechanical torque value of the machine is obtained first by using the machine's foreknown geometrical parameters and electrical parameters found by tests. Then, the magnetic flux line and density distribution and the obtained reluctance / real torque values are compared between FEM programs.
\end{abstract}

Keywords: Ansoft/Maxwell, Cedrat/Preflu, Ansys, Ansys Workbench, Induction Machine

\section{Introduction}

Applications In recent years, the FE software package have been widely used in applications. The programs using these applications are Ansoft, Ansys and Cedrat. Ansoft is the most common program among these publications although all types of machine and analysis are available in Ansys. Ansys is the world's most widely used FE software package program. Cedrat is not a very popular program.

In this study, FEM software packages were compared starting from real values on a 4-pole asynchronous machine of $1.1 \mathrm{~kW}$ [1]. As a result, it is proposed to give an idea for electrical machine designers using finite element technology. Although this test was performed only for the asynchronous machine, it is generally useful for demonstrating the advantages and disadvantages of these programs. As a matter of fact, as a result of the variations and difficulties between theoretical calculation and reality due to the working manner of the asynchronous machine, the closer a simulation program for such a type of machine to the real value the more acceptable performance given by the simpler direct-current machines.

In essence, real criterion is considered to be torque calculation. This is because magnetic flux distributions of this machine, which has been produced commercially, have already been designed within the acceptable limits. In all simulations, the material is used with a $\mathrm{BH}$ characteristic given in Fig. 1. The computer system that is used for simulations is given in Table I and specifications of the test machine in Table II.

Table 1. System Configuration

\begin{tabular}{|l|l|}
\hline Computer type & Laptop \\
\hline Manufacturer & Dell \\
\hline CPU & AMD Turion 64x2 TL-50 1.60 Ghz \\
\hline Physical RAM & 2 GB \\
\hline Graphic Card & ATI Radeon Xpress / Shared system memory \\
\hline OS & Windows 7 Ultimate 64 bit \\
\hline
\end{tabular}

${ }^{I}$ Electronic and Automation Department, Technical Sciences and Vocational School, Recep Tayyip Erdogan University, Dosma, 53100, Rize/Turkey

${ }^{2}$ Electric and Electronic Engineering Department, Engineering Faculty, Atatürk University, Campus, Erzurum/Turkey

* Corresponding Author: Email: murat.toren@erdogan.edu.tr

Note: This paper has been presented at the $3^{\text {rd }}$ International Conference on

Advanced Technology \& Sciences (ICAT'16) held in Konya (Turkey),

September 01-03, 2016.

This journal is @ Advanced Technology \& Science 2013

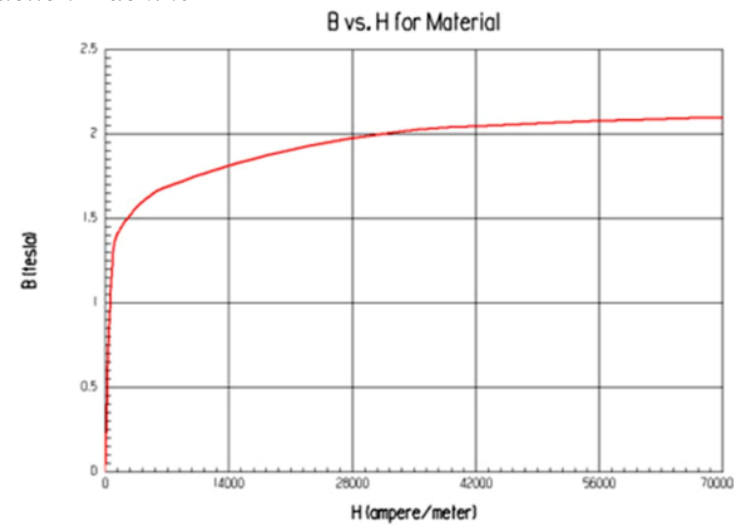

Figure1. BH curve of material used in simulations

Table 2. Test Machine Specification

\begin{tabular}{|c|c|}
\hline $\begin{array}{l}\text { Power / Frequency / Phase- } \\
\text { Connection Type }\end{array}$ & $1,1 \mathrm{~kW} / 50 \mathrm{~Hz} / 3-\mathrm{Y}$ \\
\hline $\begin{array}{l}\text { Pole number / Stator current } \\
\text { Speed }\end{array}$ & $4 / 2,7$ A / $1380 \mathrm{rpm}$ \\
\hline $\begin{array}{l}\text { Efficiency / Nominal \& } \\
\text { Starting Torque }\end{array}$ & $78 \%$ / 7,7 \& 16,9 Nm \\
\hline $\begin{array}{l}\text { Stator \& Rotor slot numbers } \\
\text { C Core Length (L) }\end{array}$ & $36 \& 28 / 65 \mathrm{~mm}$ \\
\hline $\begin{array}{l}\text { Number of turns (w1)/ wire } \\
\text { diameter }\end{array}$ & $66 / 0,51 \times 2 \mathrm{~mm}$ \\
\hline Winding type / Coil pitch & 1-layer / 8 (AAAZZZBBBXXXCCCYYY) \\
\hline $\begin{array}{l}\text { Stator (bda) / Rotor tooth } \\
\text { widths }\end{array}$ & $3,76 / 4,79 \mathrm{~mm}$ \\
\hline $\begin{array}{l}\begin{array}{l}\text { Stator (Da)\& Rotor / Shaft } \\
\text { diameters }\end{array} \\
\end{array}$ & $135 \& 79,1 / 30 \mathrm{~mm}$ \\
\hline $\begin{array}{l}\text { Stator \& Rotor slot teeth gap } \\
\text { / air gap }\end{array}$ & $2,35 \& 1 / 0,5 \mathrm{~mm}$ \\
\hline Stator / Rotor slot heights & $15,55 / 15 \mathrm{~mm}$ \\
\hline
\end{tabular}

Initially analytical expressions are obtained from the values determined by the company. After calculating emf in the stator as $192 \mathrm{~V}$ by using the air gap magnetic flux density as $0.7 \mathrm{~T}$ and heyland leakage factor, the number of conductors per slot is found, by taking the equivalent pole length factor $\alpha=0.76$, as follows,

$$
z_{0}=\frac{2 m}{N_{1}} \frac{E_{1}}{4,44 f k_{w} \phi}
$$

In here, $\mathrm{z}_{0}$ is found as 69 and $\mathrm{N} 1$ is the number of stator slots; 
$\mathrm{k}_{\mathrm{w}}=0.96$ is the winding factor and $\phi=0.0022 \mathrm{~Wb}$ is the air gap flux. The stator slot pitch induction is found from Eq (2):

$$
B_{d a}=\frac{\tau_{0}}{k_{f e} b_{d a} B_{0}(1+0,6667 \sigma)}(\mathrm{T})
$$

where, $\mathrm{B}_{\mathrm{da}}$ is stator slot pitch induction $(\mathrm{T}) ; \tau 0$, stator slot pitch; $\mathrm{b}_{\mathrm{da}}$, stator tooth width; $\mathrm{k}_{\mathrm{fe}}=0.95$ is the iron packing factor; $\mathrm{B}_{0}$ is the air gap induction ( $\mathrm{T}$ ) and $\sigma=0.0115$ is heyland leakage factor. The height of the yoke is found by using the below equation.

$h_{j 1}=\frac{\phi(1+\sigma)}{2 k_{f e} L B_{j 1}}(\mathrm{~mm})$

where, $\mathrm{L}$ is the stack length $(\mathrm{mm})$ and $\mathrm{B}_{\mathrm{j} 1}$ is the yoke magnetic flux density and assumed to be as $1.4 \mathrm{~T}$. Rotor yoke height is obtained as,

$h_{j 2}=\frac{\phi}{2 k_{f e} L B_{j 2}}(\mathrm{~mm})$

In here, the rotor yoke height is taken as $1.2 \mathrm{~T}$. Leakage reactance of stator winding is,

$$
X_{\sigma 1}=0.5 \frac{\pi^{2}}{f} w_{1}^{2} \lambda_{1}(\Omega / \text { phase })
$$

where, $\lambda_{1}=12.46$ is the leakage conductance of stator winding. Then, the leakage reactance of rotor bars reduced to stator is obtained from (Eq (6)).

$$
X_{\sigma 21}=1,6 u_{1} \pi^{2} \lambda_{2}(\Omega / \text { phase })
$$

where, $\lambda_{2}=19.63$ is the leakage conductance of stator winding and $u_{1}=6.67 \times 10^{4}$ is the conversion rate. The leakage factor of the rotor is obtained as,

$\sigma_{2}=\frac{X_{21}}{X_{1}} \sigma_{1}$

Then, nominal and startup moments found from the equivalent circuit parameters are obtained as follows, respectively:

$$
\begin{aligned}
& T_{1}=1+\sigma_{1} \\
& X_{k}=T_{1} X_{1}+T_{l}^{2} X_{21}
\end{aligned}
$$

By using the above relationships, the nominal moment,

$$
M_{d n}=\frac{60}{2 \pi n_{s}} m\left(\frac{U}{\sqrt{3}}\right)^{2} \frac{R_{21} / s}{\left(R_{1}+T_{1} R_{21} / s\right)^{2}+X_{k}^{2}}(\mathrm{Nm})
$$

and the startup moment,

$$
M_{d y}=\frac{60}{2 \pi n_{s}} m\left(\frac{U}{\sqrt{3}}\right)^{2} \frac{R_{21}}{\left(R_{1}+T_{1} R_{21}\right)^{2}+X_{k}^{2}}(\mathrm{Nm})
$$

are found as 7 and $16.84 \mathrm{Nm}$, respectively. Here, $\mathrm{U}$ is the voltage at motor end; $\mathrm{n}_{\mathrm{s}}$ is synchronous speed; $\mathrm{m}$ is the phase number; $\mathrm{T}_{1}$ is the conversion rate; $R_{1}$ and $X_{1}$ are resistance and reactance of stator winding, respectively, and $\mathrm{X}_{\mathrm{k}}$ is the short circuit reactance.

\section{The Programmes for Electric Machine Design with Fem}

\subsection{Ansoft}

Of the products of Ansoft [2-13], Maxwell v2.6 is investigated for 2D applications, Maxwell v11.1 for 3D applications and the electrical machines module rxmprt v5 was examined. The visual quality, performance, advantages and disadvantages of this program in 2D and 3D applications were investigated and, information was given about them.

Advantages of Ansoft / Maxwell;

\section{- Electrostatic analysis and a geometry module are available for electrical machines:}

The geometry of the machine is generated with rmxprt integrated as a module by using Maxwell v11.1 2(3/3) 3 D program and this can be used with the versions 2.4 or 2.6 for $2 \mathrm{D}$ analysis. Almost all electrical machine geometry in 2D or 3D can be generated easily by v11.1 developed for Maxwell 3D applications and the rmxprt module integrated into it.

- A translator module is available for AutoCad file: A useful module, called a translator, is available in Maxwell control panel that converts Autocad DXF files, etc. to sm2.

- Very easy-to-use:

The geometry part can be easily skipped in this program by converting the AutoCAD files to sm2 format with a translator. In addition, any electrical machine generated with rmxprt program can easily be exported in 2D. The BH curve can easily be obtained directly from txt file.

- Winding tool is available:

Winding tool availability in the program provides convenience to the designer.

\section{- Graphical performance is high:}

Maxwell 11.1 provides an excellent graphics performance in 2D/ 3D applications. Drawing can be easily managed with handy shortcuts using the mouse. The size of the shape does not cause much decrease in performance. Even a synchronous generator with an internal diameter of $2 \mathrm{~m}$, an outer diameter of $2.8 \mathrm{~m}$ and a depth of $30 \mathrm{~cm}$ takes up the a space of approximately $600 \mathrm{MB}$ and offers a superior graphics performance.

- Graphical plotting specifications are sound:

Plotting can be performed easily and a plotting form can be obtained including the number of lines.

- High solution speed:

Solution part progress is very fast

- Memory and CPU performance is good:

Program memory is suitable as drawings do not occupy too much space and the processor performances provide the results in a short time.

Disadvantages;

- Static Analysis:

It does not allow professional solutions with respect to the static analysis.

- DOS view for 2D applications:

The graphical interface of Maxwell v2.6 used for 2D applications is similar to the DOS programs.

- Direct AutoCAD integration is weak:

Integration is not possible for direct intervention in the AutoCAD files.

- Moderate accuracy:

Magnetic flux density distribution is shown in Figure 2. Although the reluctance torque values obtained as $5.53 \mathrm{Nm}$ is not the realistic value, Ansoft can easily bring the simplicity together with the mastership. (Torque value is $-5.53 \mathrm{Nm}$ ).

- Inadequate help menus:

Help files achieved by F1 button on the program menu are inadequate. 
In conclusion, opportunities offered by Ansoft[14] will be very useful for the researchers who will begin Magnetic field static analysis with finite elements method for the first time.

\subsection{Cedrat}

Preflu2d v10.3.2 program [15-18] of the Cedrat group is analyzed here. Cedrat classifies its products as $2 \mathrm{D}$ and $3 \mathrm{D}$. The visual quality, performance, advantages and disadvantages of this program in 2D and 3D applications were investigated and, information was given about them.

\section{Advantages of Cedrat / Preflu:}

\section{- Electrical machines module is available:}

The design part of the electrical machine is the result of an original design. In Cedrat's design module, the part that is moving or the part which is fixed can be entered and a good machine geometry can be created. The meaning of the parameters in the designed asynchronous machine geometry can be displayed in the figures (with animations) available on the ready overlayers.

\section{- Armature reaction is taken into account:}

In Figure 3, it can be seen that the magnetic flux lines are different from the Ansoft and Ansys programs. This is Cedrat taking the armature reaction into account and this really seems to be a significant advantage by itself.

- Winding tool is available:

The winding tool available in the program provides convenience to the designer.

- Mechanical torque calculation is available:

A mechanical torque calculation by Cedrat is a good specification although it can hardly approach the real torque value as can be seen in Table 3 .

\section{- Electrical circuit module is available:}

The electrical circuit diagram of the machine is handled separately by the Cedrat. The values of circuit elements cannot be seen with these specifications offering the possibility of making any kind of connections. Furthermore, one has to enter resistance and inductance values of each phase into the program, as external data requires the use of other programs.

\section{- Graphical interface is good:}

The graphical interface is designed well although it is not as good as Ansoft.

\section{- Graphics performance is satisfactory:}

Graphical result unit of Cedrat generates values suitable with what to do. Understanding of the results takes a short time with the help files. Graphics are found as desired and features of the results part make a good impression.

\section{- Graphical plotting specifications are very handy:}

It is possible to obtain a variety of parameters graphically and animation features are fairly advanced in graphic illustrations. Harmonic analysis can be represented graphically in spectral analysis and this makes Preflu of the Cedrat one-step ahead. In addition, all graphics can be shown in the same axis in a single window.

\section{- Solution speed is moderate:}

It is observed that the solution speed generates solutions at normal speed compared to other programs when it is considered to make the memory stacked.

Disadvantages:

\section{- 2D and 3D applications are separated:}

This is disadvantageous for those who wish to work both in 2D and in 3D.

\section{- Hard-to-use:}

The web browser is opened by pushing the help button and the help files follow here. In addition, there is no help file on the machine design in the help file menu giving information for a designer who will design an electrical machine regarding how to start the designing process and perform it. Sample files given by the Cedrat team must be installed. If a project is designed by using overlay, the coordinate system is not generated as in the sample given by the team and it fails. It becomes a time consuming process to generate exactly the same coordinate system given in the sample.

\section{- Moderate accuracy:}

Preflu obtains $2.96 \mathrm{Nm}$ with Ansoft results for a quarter of the designed machine and this would be $11.84 \mathrm{Nm}$ for whole machine. $9.68 \mathrm{Nm}$ would be found by using the analytical inputs. Tests show that the torque generated is too dependent on the rotor leakage reactance (resistance and inductance of the portion of end rings between two adjacent bars). Accordingly, rotor leakage reactance values are seen to give improper results. - Inadequate help menus:

Access to all subjects and examples/samples in the help file is not possible either in html or pdf formats from a single location. French expressions are found in the help menus. Incomprehensible points and inconsistencies exist between the sample asynchronous machine in the help file and the present version and, there is no information regarding the use of the over layers.

\section{- Intensive memory and disk usage:}

When a file is opened in Preflux2D, it occupies more than 1 GB (ram + virtual memory) according to status of the computer hardware. A number of programs running at once pose a problem even in today's computers. Moreover, with the addition of solution program block, results in a memory of 2 GB. It is difficult to open two files together in Cedrat. It is a time consuming process to open your project.

In conclusion, even if you believe you are doing everything correctly in Cedrat/ Preflu[19], the odd bugs may be found(such as node error). Technical support is needed for this program throughout the time that you are inexperienced in using it.

\subsection{Ansys Multi Physics}

In this part, the Ansys version v11 and the Ansys Multi Physics program [20-29] are analyzed.

Advantages of Ansys Multi Physics:

\section{- Adequate help menus:}

Help files are very useful. When investigating a topic in the help files, surfing is possible within the program just as in MATLAB and there is no need for any program for this. This also provides a possibility to learn about unknown topics. Help files contain brief information.

\section{- 2D and 3D applications are together:}

This is advantageous for those who wish to design both in $2 \mathrm{D}$ and in 3D.

\section{- Opening speed of the project is high:}

Opening speed of your project is very high.

- Graphics performance is satisfactory:

Shape of magnetic flux distribution is the same for tri-shaped meshing while $1-2 \%$ change occurs in the resulting values. Magnetic flux distribution is given in Fig. 2. Tri-shaped meshing and this flux distribution are realistic. This is because the torque calculation reaches to its actual value, e.g. $8 \mathrm{Nm}$. The types of elements are specified in Ansys and all details of FEM are examined. A BH curve of the material can be completely made through "copy and paste" at a time as a text file from a file. This feature is not contained by the other two programs.

- Very good accuracy:

- The torque value obtained by ansys for the machine to be designed is $6.43 \mathrm{Nm}$. The actual torque value, $7.6 \mathrm{Nm}$. is a satisfactory value for a company that does not develop simulation programs specific for electrical machines such as Cedrat. 


\section{- Solution speed is good:}

Solution speed gives rapid results concerning the generation of realistic values despite the fact that it is not a program developed for electrical machine design.

\section{Disadvantages;}

\section{- Graphical plotting specifications are difficult.}

Integration cannot be satisfied in plotting graphics which results in plotting that is completed in more than one stage. Since the menus of Ansys Multi Physics are inadequate, plotting graphics is a troublesome process.

\section{- Graphical interface is inadequate:}

Drawing sizes should be corrected with a scale factor if they are not in meters since Ansys takes geometric sizes in meters. Assigning material properties should be performed one by one as no tree exists for this feature in the program. Undo and modify functionalities for the processes made before in a project saved in the program are very complex. Dynamic model mode icon in the menu should be used every time for zooming and dragging of a geometry in the graphical interface and then cancelled.

\section{- Electrical machines module is not available:}

There is no electrical machine design module. Design is made by integration with conversion of an Autocad or Solidwork job.

\section{- Hard-to-use:}

The electromagnetic sample solution in Ansys is discussed through a very simple problem. Therefore, one will definitely have great difficulty in a real project.

\section{- Intensive memory and disk usage:}

Two projects cannot be opened at a time n Ansys. Each project takes up approximately $600 \mathrm{MB}$ in virtual memory and about $17 \mathrm{MB}$ in active memory. Ansys occupies nearly $1 \mathrm{~GB}$ in the hard disk during simulation. In addition, it uses an excessive part of the memory during simulation. Simulation results of a $1.1 \mathrm{~kW}$ motor take up a space of $1.26 \mathrm{~GB}$ with the file where everything is saved. This is because one has to work at full scale.

In conclusion, Ansys Mult1 Physics program is a difficult multidisciplinary program for initial design although it has rapid and superior features in several points.
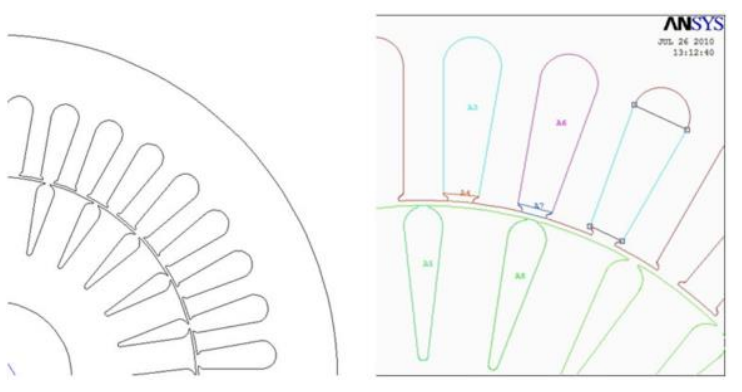

Figure 2. 2D CAD file and fields obtained with Ansys

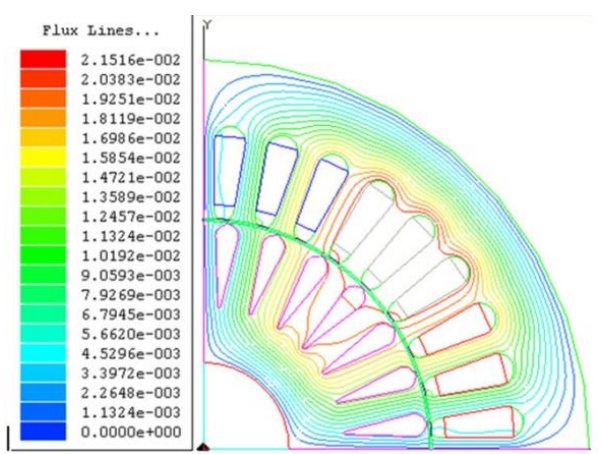

a) Ansoft

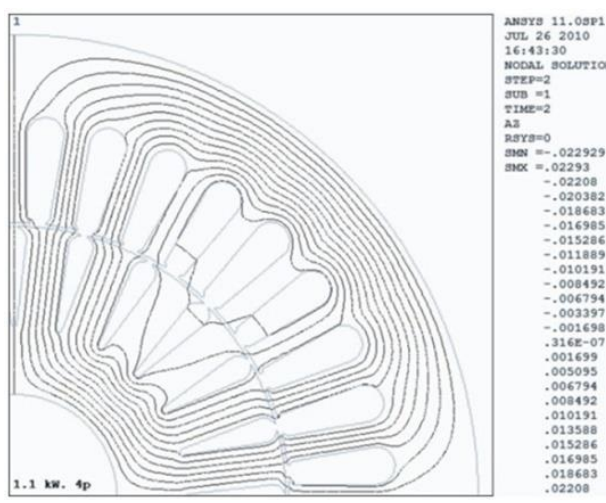

b) Ansys

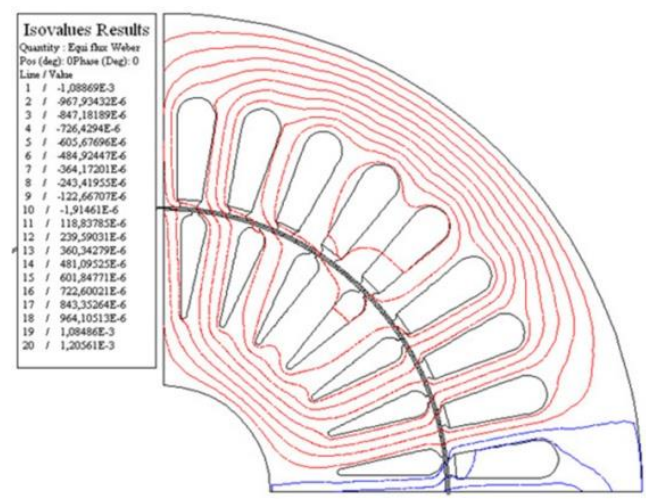

c) Cedrat

Fig. 3. Magnetic flux line diagrams of $1.1 \mathrm{KW}$ induction machine in FE Software

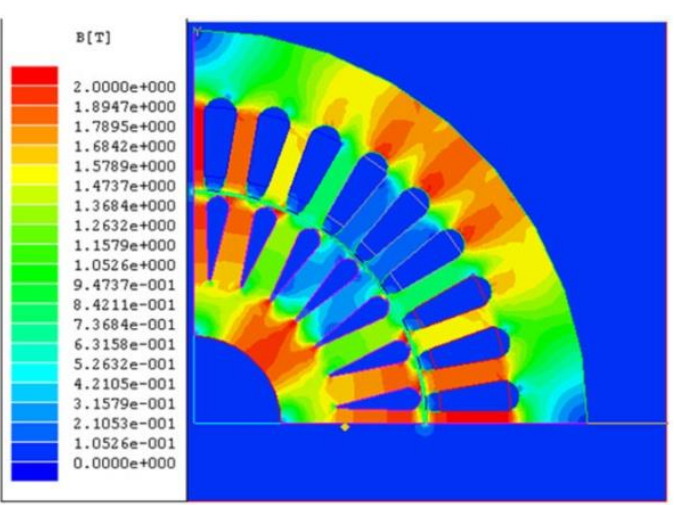

a) Ansoft

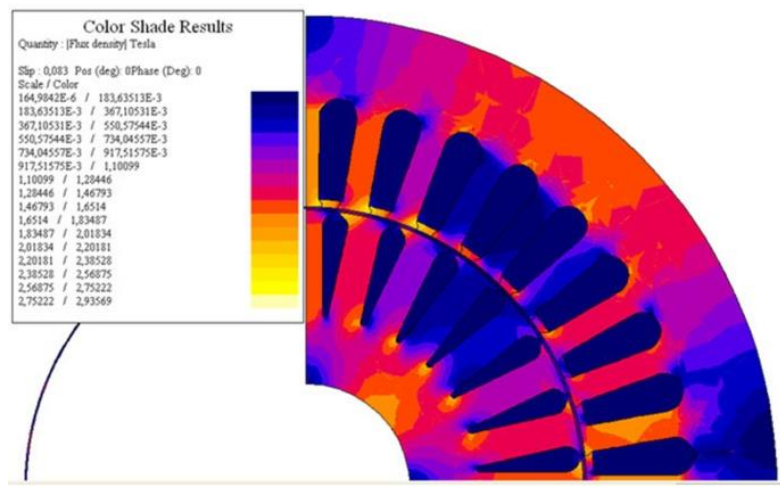

b) Cedrat 


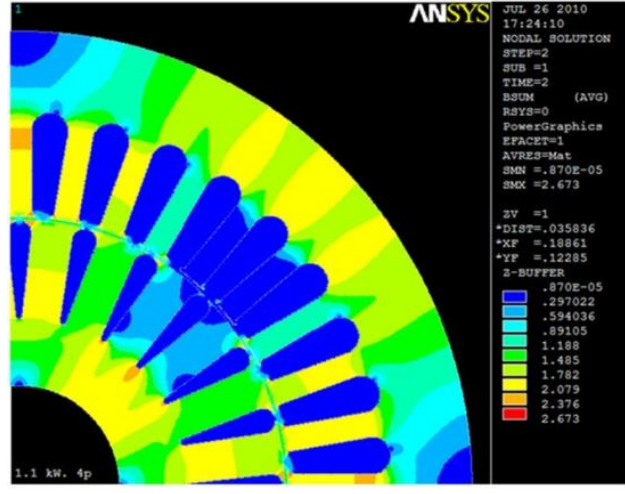

c) Ansys Multi Physics (Quadratic-shaped mesh)

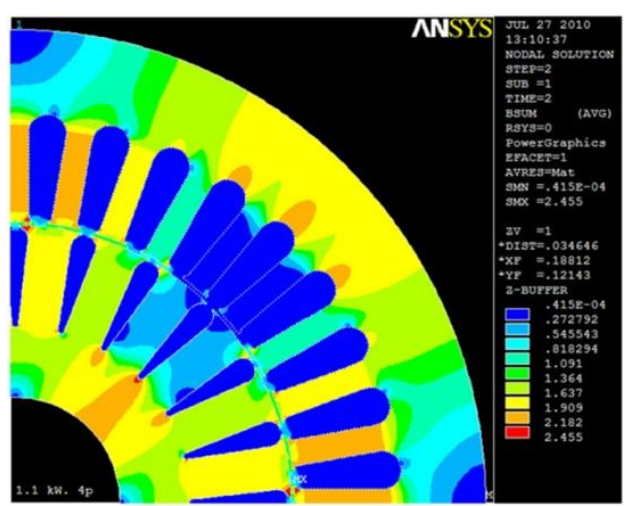

d) Ansys Multi Physics (Tri-shaped mesh)

Figure 4. Magnetic flux density diagrams of $1.1 \mathrm{KW}$ induction machine

\subsection{Ansys Work Bench}

Ansys workbench program [20-29] is investigated and its advantages and disadvantages are given in comparison to other programs.

Advantages of Ansys Workbench[30]:

\section{- Adequate help menus:}

Help files are very useful. When investigating a topic in the help files, surfing is possible within the program just as in MATLAB and no program is needed for this. This also provides the possibility to learn about unknown topics. Help files contain brief information.

- 3D applications are powerful:

Work bench is actually designed as 3D. This is a simplicity for those working in $3 \mathrm{D}$.

- Opening speed of the project is high:

Opening speed of your project is very high.

- Graphics performance is satisfactory:

It has a better graphical interface compared to Ansys Multi Physics. It includes similar features to Autocad. A number of shapes can be formed easily.

Disadvantages:

\section{- Graphical plotting specifications are difficult.}

Integration cannot be satisfied in plotting graphics which results in plotting being completed in more than one stage. Since the menus of Ansys Multi Physics are inadequate, plotting graphics is a troublesome process. As given in Figure 4, deterioration can be seen while getting closer to the drawing.

\section{- 2D application is weak}

As given in Figure 5, points that should be round are taken as flat directly in Workbench. 2D fields generated by Ansys Multi Physics cannot be generated in Work bench. Here, in order to make surfaces from sketches, the shape should be drawn in work bench by proceeding on the shape, and thus generating new construction points. However, this is difficult for a complex shape such as an asynchronous machine. As can be seen from Figure 6, the appearance of strange arrows with 3D because of this process indicates that 2D application has failed. After defining the two axis, missing or additional fields/areas should be removed or merged one by one, as can be seen from Figure 7. Although the angle between 28 rotor slots of our machine is $12.857^{\circ}$, a close fit is ensured on the axis while this cannot be provided on other points (Figure 8).

- Graphical performance is low:

Total graphical performance decreases as the number of defined surfaces increases even during study in $2 \mathrm{D}$. As can be seen from Figure 10, the geometric shape made in multiphysics and imported in 3D gives face-face inconsistency error.

- Electrical machines module is not available:

The fact that workbench cannot be fully integrated with sat files imported from Autocad is a huge deficiency. Although it has satisfactory specifications, work bench is not useful for electrical machines. At minimum the generation of cores of asynchronous machine is three to four times more difficult due to the Autocad integration problem.

\section{- Hard-to-use}

Despite the fact that the Workbench in Ansys provides some convenience for Mechanical engineering activities, obtaining geometries and design creation is difficult for most designers. Most of the conveniences offered by Autocad is not available for lines in Workbench. The pattern command corresponding to polar and angular array command, which is indispensable for electrical machine designers, should be improved.

Intensive memory and disk usage:

Workbench requires a memory of $2 \mathrm{~GB}$ (650 MB ram + virtual memory) for our $3 \mathrm{D}$ project shows that the program is definitely a memory monster.

As a result, work bench is considered to be a hard-to-use program for electrical machine designers (even geometry construction is difficult) although it has a handy interface.

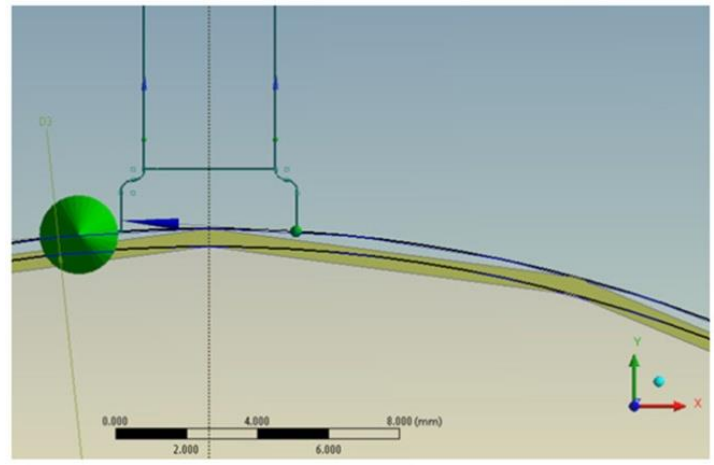

Figure 5. The Project of test machine in Ansys Workbench

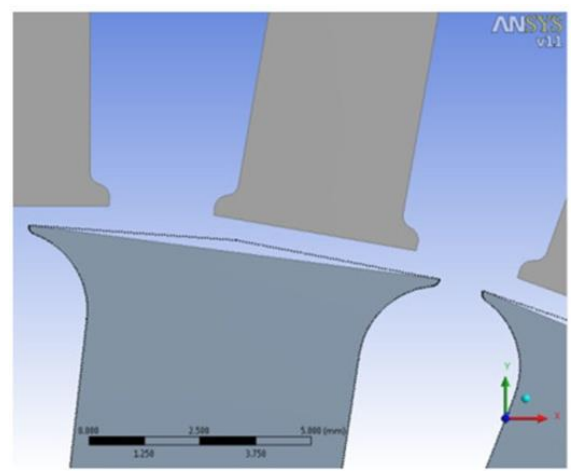

Figure 6. The deformation of imported geometry 


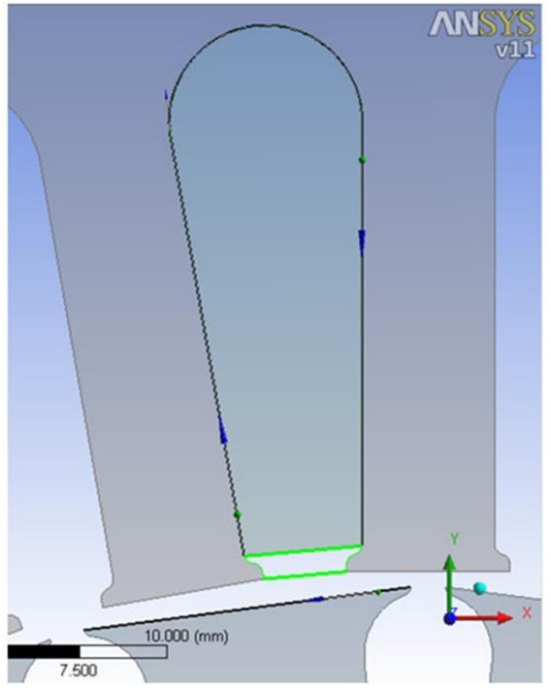

Figure 7. Creating regions in Ansys Workbench.

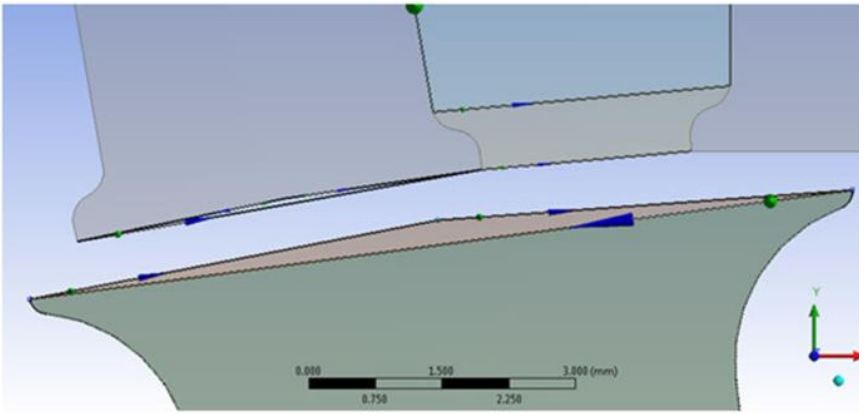

Figure 8. Reforming the geometry after deformation in Ansys workbench

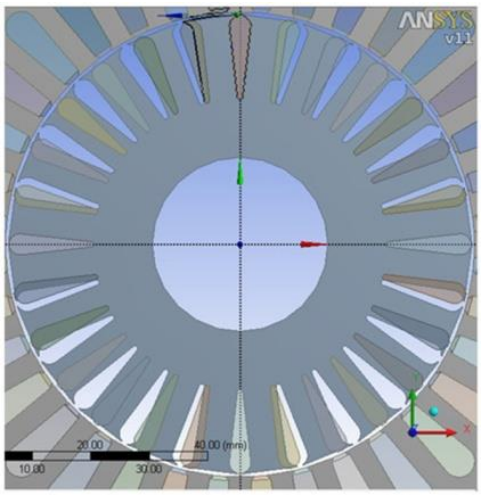

Figure 9. The slipping of the regions of rotor bars after pattern process. Notice the location on axis.
Table 3.Comparison of Torque Values (Nm)

\begin{tabular}{|l|c|c|c|}
\hline Torque Type & Reluctance & Mechanic & Accuracy \\
\hline Real & - & 7,7 & - \\
\hline Analytic & - & 7,6 & $98 \%$ \\
\hline Ansoft / Maxwell & 5,53 & - & $72 \%$ \\
\hline Cedrat / Preflu & 9,68 & & $78 \%$ \\
\hline Ansys / multiphysics (quadratic mesh) & 6,44 & - & $84 \%$ \\
\hline Ansys / multiphysics (tri-shaped mesh) & 8,0 & - & $96 \%$ \\
\hline
\end{tabular}

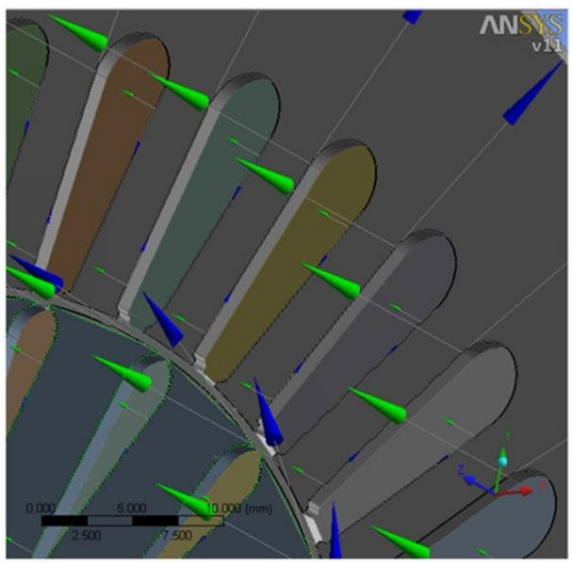

Figure 10. 3D geometry in Workbench after the import process

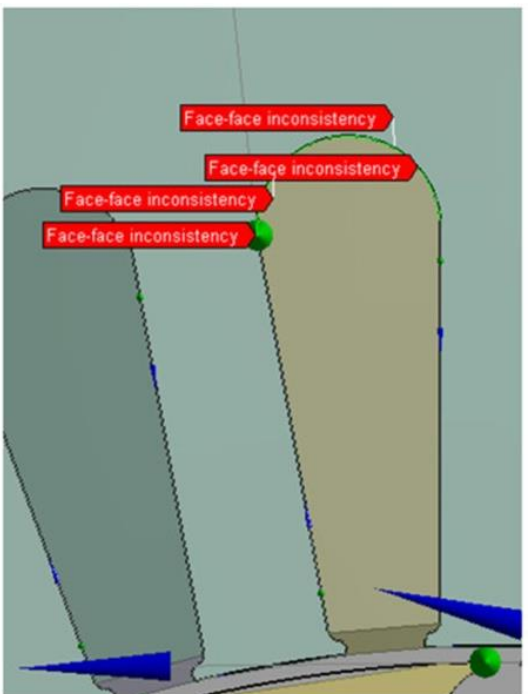

Figure 11. Workbench errors in 3D geometry after import process.

Table 4.Comparison of FEM Softwarepackgets

\begin{tabular}{|c|c|c|c|c|c|c|c|c|}
\hline Software & Version & Usage & $\begin{array}{c}\text { Electric } \\
\text { Machiner } \\
\text { y Module }\end{array}$ & $\begin{array}{c}\text { Auto CAD } \\
\text { file } \\
\text { integration }\end{array}$ & $\begin{array}{c}\text { Graphic } \\
\text { Performance }\end{array}$ & $\begin{array}{c}\text { Memory / } \\
\text { Disk } \\
\text { performance }\end{array}$ & $\begin{array}{c}\text { Overall } \\
\text { performance }\end{array}$ & Accuracy \\
\hline $\begin{array}{c}\text { Ansoft / } \\
\text { Maxwell }\end{array}$ & $2.6 / 11.1$ & Easy & Exist & Poor & Very Good & Good & Good & Average \\
\hline $\begin{array}{c}\text { Cedrat/ } \\
\text { Preflu }\end{array}$ & 10.3 .2 & Difficult & Exist & - & Good & Average & Good & Average \\
\hline $\begin{array}{c}\text { Ansys / } \\
\text { multiphysic } \\
\text { s }\end{array}$ & 11 & Hard & No & Excellent & Very Good & Good & Very Good & Very Good \\
\hline $\begin{array}{c}\text { Ansys / } \\
\text { Workbench }\end{array}$ & 11 & Average & No & Good & Bad & Poor & Poor & - \\
\hline
\end{tabular}




\section{Conclusion}

As can be seen from Figure $2 a$ and $2 b$, the magnetic flux line distribution is similar between Ansoft and Ansys since both Pittsburg companies work together. In addition, a complete symmetry is observed in each simulation while it is not observed in the diagram of Cedrat. This is because armature reaction may also be taken into account with Cedrat. As magnetic flux lines cannot be perfectly symmetrical at this point due to the armature reaction, it can be considered that Cedrat is one-step ahead of the others. The reason why Cedrat's geometry/drawing appears more realistic with respect to the magnetic flux density distributions may be the fact that Cedrat takes realistic windings values by taking the number of turns into consideration. Magnetic flux density distributions are not exactly true values since the excitation parameter is entered as area-based like $\mathrm{A} / \mathrm{m}^{2}$ in the other two programs.

Based on the torque values given in Table 3 Ansys multi-physics is better than the others. Ansoft shows brilliant performance with respect to ease of use according to Table 4. The Ansys-Ansoft partnership gives clues that the two companies will be able to reach a better position in the future.

The subject of which parameters would be accepted as criteria with respect to which program to be used in terms of engineering problems is a controversial point; however it can be considered that Ansys multi-physics is the best if torque values are considered as the most important factors for electrical machines. The fact that Cedrat is able to make mechanical torque calculation is considered a nice feature. Cedrat may be in a very important position in the long term with respect to electrical machines. However, it should give more realistic results for the torque calculation. Ansys multi-physics is seen as being unrivaled regarding multidisciplinary applications. However, its graphical interface needs a lot of improvement. The compatibility of multiphysics with Auto CAD and the closeness of torque values to realistic values stand out as a big advantage although it does not have any electrical machines module. An electrical machines module is available in Ansys and this makes its usage exclusive. Ansys Workbench should get technical support from Ansoft Company in order to eliminate the deficiencies in graphical interface. Electric machines designers cannot choose workbench in its present condition.

In conclusion, Ansoft / Maxwell is a convenient choice for junior engineers using a FEM software package for the first time. For those who desire to achieve more realistic results, Cedrat would be suitable with its superior electrical machines module and outstanding performance. Due to the fact that an electrical machine that will be manufactured commercially must be analyzed mechanically, structurally and with respect to cooling and viscosity when needed. Ansys multi physics which is very successful in achieving realistic results and unrivaled in multidisciplinary applications should be the first choice for professional engineers although it doesn't have the features for providing great convenience such as in Ansoft and Cedrat and it is hard-to-use.

\section{References}

[1] Volt Electric, Kemalpaşa,İzmir,Turkey, URL http://www.voltmotor.com.tr/home/products/generalpurpose-motors/3-phase-motors/?ID=13

[2] D. Lin, P. Zhou, Z.J. Cendes, S. Stanton, W.N., Fu, A dynamic analytical model of switched reluctance motors.
International Conference on Electrical Machines and Systems, 2005: p. 509 - 514.

[3] D. Lin, P. Zhou, Z.J. Cendes, Analytical prediction of cogging torque in spoke type permanent magnet motors. International Conference on Electrical Machines and Systems, 2008: p. 1 - 5.

[4] D. Lin, P. Zhou, An improved dynamic model for the simulation of three-phase induction motors with deep rotor bars. International Conference on Electrical Machines and Systems, 2008: p. 3810 - 3814.

[5] F. Bao, X.Liu, J. Hu, H. Han, Y. Liu, L. Cheng, Free piston tubular permanent-magnet linear generator based on electromagnetic field analysis. 2010 International Mechanic Automation and Control Engineering (MACE) Conference, 2010: p. 3623-3626.

[6] H. Yang, C.Gu, Analytical design and modelling of transverse flux switched reluctance machine. 2008 International Conference on Electrical Machines and Systems ,ICEMS, 2008: p. 3414 - 3416.

[7] K.N. Srinivas, R. Arumugam, Circuit simulation of dynamic performances of the switched reluctance motor. Electrical and Electronic Technology, TENCON. Proceedings of IEEE Region 10 International Conference 2001, 2001: p. 592 - 596.

[8] L. Yuelun, W. Mianhua, W. Yan, W. Fenli, Simulation Research on Switched Reluctance Motor Modeling and Control Strategy Based on ANSOFT. Measuring Technology and Mechatronics Automation (ICMTMA) Conference, 2010. 3: p. 374-377.

[9] P. Zheng, J. Wang, R. Liu, H. Jiang, S. Cui, S. Cheng, Performance calculation of brushless DC motor. International Conference on Electrical Machines and Systems, 2005. 1: p. $426-428$

[10] X. Liu, W. Zhang, F. Jiang, A new rotor type of cascaded brushless doubly-fed machine", . Electrical Machines and Systems, ICEMS, 2005. 1: p. 734-737.

[11] X. Peng, H. Guo, Electromagnetic analyzing of slotless evaporative cooling generator. International Conference on Electrical Machines and Systems, 2008: p. 4192 - 4194.

[12] Z. Bingyi, L. Bingxue, F. Guihong, Z. Fuyu, Research of Multipolar Permanent Magnet Synchronous Submersible Motor for Screw Pump. Mechatronics and Automation, ICMA, 2007: p. 1011 - 1016.

[13] Z. Bingyi, W. Rui, Z. Fuyu, F. Guihong, Study of improving low frequency torque ripple in low speed and high torque PMSM. International Conference on Electrical Machines and Systems, 2007: p. 847 - 852

[14] Ansoft, help document,URL http://ansoftmaxwell.narod.ru/english.html

[15] G. Ugalde, G. Almandoz, J. Poza, A. Gonzalez, Computation of iron losses in permanent magnet machines by multi-domain simulations. European Conference on Power Electronics and Applications, 2009: p. 1 - 10.

[16] H. Jussila, P. Salminen, M. Niemela, J. Pyrhonen, Guidelines for Designing Concentrated Winding Fractional Slot Permanent Magnet Machines. International Conference on Energy and Electrical Drives, 2007: p. 191 - 194.

[17] H. Jussila, P. Salminen, M. Niemela, J. Pyrhonen, A. Parviainen, A. Nerg, Concentrated winding axial flux permanent magnet motor with plastic bonded magnets and sintered segmented magnets. International Conference on Electrical Machines and Systems, 2008: p. 1-5.

[18] R. Le Letty, F. Claeyssen, P. Gonnard, B. Hamonic, 
Combined finite element-normal mode expansion methods for ultrasonic motor modeling. IEEE Proceedings of Ultrasonics Symposium, 1994: p. 531 - 534

[19] Cedrat, help document,

URL http://www.cedrat.com/en/software-solutions/flux/faq.html.

[20] C. Luo ,X. Wang, P. Ning, The analysis of stator MMF and the calculation of rotor losses in a 12-phase high speed asynchronous generator. International Conference on Electrical Machines and Systems, 2005: p. 690 - 694.

[21] C.G.C. Neves, F. Runcos, M.V.F. da Luz, Y. Lefevre, 3D electromagnetic simulation of a claw-pole generator. International Symposium on Power Electronics, Electrical Drives, Automation and Motion, 2006: p. 1430 - 1433.

[22] C.S. Zhang, Y. Fan, G.G. Li, H.Y. Chu, The sinusoidal airgap magnetic field design of axial flux permanent magnet synchronous motors. International Conference on Electrical Machines and Systems, 2005: p. 340 - 343.

[23] F. Guihong, W. Lifeng, Z. Bingyi, S. Guanggui, Z. Zhongxian, Analysis of magnetic field for low speed and high torque permanent magnet synchronous machine. International Conference on Electrical Machines and Systems, 2003: p. $778-781$.

[24] F. Yaojing, C. Wanli, Y. Kai, G. Chenglin, Design and optimization of Servo Permanent Magnetic Synchronous Motor. International Conference on Electrical Machines and Systems, 2008: p. 3307 - 3310.

[25] F. Yaojing, Y.Kai, G. Chenglin, Design and optimization of external-rotor torque motor. International Conference on Electrical Machines and Systems, 2009,: p. 1 - 4.

[26] H. Guan, Z. Zhao, S. Meng, Dynamic meshing for the circuit-field analysis of inverter-driven induction motor. International Conference on Electrical Machines and Systems, 2003: p. 834 - 836.

[27] J. Xia, T. Dong, C. Wang, J. Zhao, Low speed high torque PMSM design based on unequal teeth structure. International Conference on Electrical Machines and Systems, 2008: p. 3274 - 3277.

[28] M. Mardiha, M. Vakilian, M. Fardmanesh, Design and electromagnetic analysis of a superconducting rotating machine. Power Engineering Conference, 2008: p. 1 - 3.

[29] X. Deng, G. Tang, H. Zhang, X. Zhang, Finite element method analysis of the electromagnetic field of Brushless Doubly-Fed Machine. International Conference on Electrical Machines and Systems, 2008: p. 346 - 350.

[30] Ansys, help document, URL http://www.ansys.com/Support/Documentation 